\title{
Geometry Effect Investigation on a Conical Chamber with Porous Media Boundary Condition Using Computational Fluid Dynamic (CFD) Technique
}

\author{
Yazid Bindar \\ Chemical Engineering Research Group on Energy and Processing System \\ Chemical Engineering, Study Program, Faculty of Industrial Technology \\ Institut Teknologi Bandung \\ dhiebindar@yahoo.com
}

\begin{abstract}
The present study is an attempt to introduce a method for optimizing the geometry of a unit process. The comprehensive unit process performances are generated by a CFD engine. The CFD engine can simulate the unit process performances at whatever conditions. Both design geometry and operating variables were used on the CFD simulation. The burden on a simplified process was taken out from CFD simulation. A complex geometry of a unit process is represented by a secondary reformer. A secondary reformer has a conical chamber as a space to undergo a combustion reaction before entering a catalyst bed. This complexity is added by the boundary on a porous solid surface as the top surface of the catalyst bed. The conical angle affects the flow pattern inside the conical chamber having a porous solid surface as its base. The conical angle above $65^{\circ}$ results the disappearing of the recirculation flow. The inlet distance from the porous solid surface also can exhibit different characteristics of recirculation flow. The closer the distance to the porous solid surface, the stronger the recirculation is. The inlet velocity values have no significant effect on the flow pattern. The introduction of a solid volume inside the geometry creates distortion in the flow pattern. In the application, the inserted solid volume is equivalent to a burner. It means that the use of the burner inherently produces some problems of the flow distribution.
\end{abstract}

Keywords: geometry optimization; CFD technique; conical chamber.

\section{$1 \quad$ Introduction}

In conventional optimization, the object function is used to be maximized or minimized in term of the variables which may be unconstrained or constrained [1]. The process variable optimization uses the object function method. For geometry optimization, the variables are geometry and process variables. The object function in geometry optimization is not as straight forward as that in process variable optimization. The full picture of the unit process performance is definitely required to formulate the conclusion which geometry produces the targeted performances. 
The full picture of the unit process performance is characterized by the distribution of the process performance indicators, such as concentration, temperature, velocities and others, over the space and time. The spatial performance of the variable indicators should be generated at least for two dimensional space or mostly three dimensional one to be more realistic.

The governing law for each variable in the spatial and temporal multidimension is the conservation law. The velocity variation over space and time is represented by the momentum conservation law. The basic momentum law is recognized as Navier-Stokes equation. The temperature distribution is based on the energy conservation spatially and temporally. The species concentration profiles are dictated by the mass conservation laws. These basic laws are well prescribed by [2].

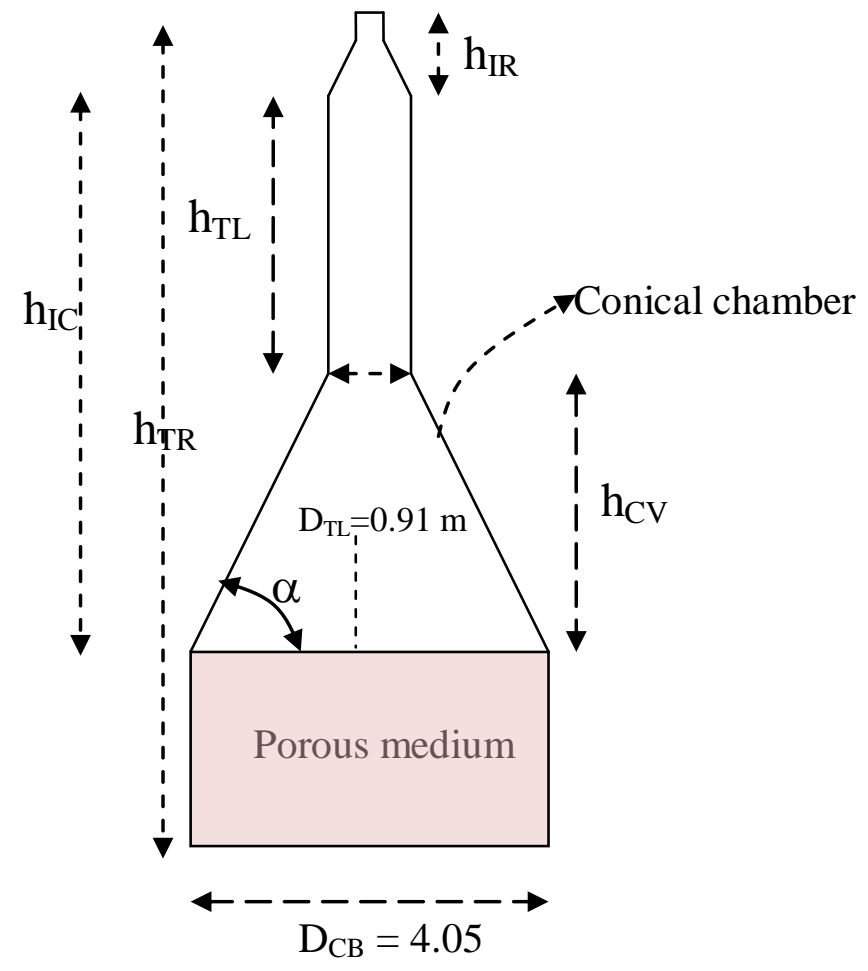

Figure 1 A diffuser combustion volume prior to the catalyst bed.

With advanced improvement in the fluid flow modeling, the turbulent flow has been successfully modeled. One of the suitable turbulent models or most of engineering problems is turbulent kinetic energy $(\mathrm{k})$ - turbulent dissipation rate

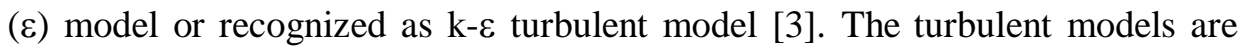


linked to the momentum, mass and energy equations. Other effects such as convection, radiation, mixing and chemical reaction can also be modeled. At this condition, the complex phenomena in the unit process become solvable.

The numerical method and the computer power revolution have opened the gate to dig more about spatial and temporal performance of the unit process. The numerical method on fluid flow is translated into a power computational engine, called Computational Fluid Dynamic code (CFD code). CFD is a numerical engine to generate spatial and temporal performances of the unit process. The variations of geometry can be investigated numerically to obtain the optimum geometry form of the unit process.

The geometry of a secondary reformer is formed by smaller diameter of transfer line of gas synthesis and a larger diameter cylindrical reactor vessel. A smaller transfer line is connected to the larger reactor vessel through a diffuser or conical chamber. The base of the diffuser is made of protective refractory bricks which are channeled by many vertical holes. A typical shape of the secondary reformer is shown in Figure 1. This conical chamber is usually dedicated for a combustion zone.

The intuitive solution to overcome the poor mixing problem is to redesign the burner geometry and arrangement. This concept is well presented by Farnell [4]. $\mathrm{He}$ also introduced the CFD method to redesign the burner. However, the flow structure within the conical chamber has not been yet well investigated. The main focus there was the secondary flow in the conical chamber. The role of the secondary flow on the mixing needs to be formulated. A comprehensive understanding on the effect of the geometry of the unit process, such as a secondary reformer, require some optimization work focusing on geometry. Since the present of burner itself destructs the flow structure, the flow characteristics without the burner should be well presented.

The objective of this study is to optimize geometrically the conical combustion chamber. The focus is paid to build the understanding of the fluid flow structure in a conical chamber having the porous type media in the larger base of conical region. The combustion is not included for this time. For the sake of simplicity and obtaining more figures of the flow, the conical chamber to be considered in this study is only two dimensional geometry. The results are useful to understand the fluid flow structures. A three dimensional investigation actually can be done However this will be conducted for the next studies. 


\section{$2 \quad$ Fundamental}

All governing equations of the process variables are expressed in a general partial differential equation form for variable $\Phi$,

$$
\frac{\partial \rho \Phi}{\partial \mathrm{t}}+\mathrm{u}_{\mathrm{i}} \frac{\partial \rho \Phi}{\partial \mathrm{x}_{\mathrm{i}}}=\frac{\partial}{\partial \mathrm{x}_{\mathrm{i}}}\left(\Gamma_{\Phi} \frac{\partial \Phi}{\partial \mathrm{x}_{\mathrm{i}}}\right)+\mathrm{S}_{\Phi}
$$

The variable $\Phi$ can be velocity components $(\mathrm{u}, \mathrm{v}, \mathrm{w})$, species concentrations $\left(\mathrm{Y}_{\mathrm{i}}\right)$, energy (temperature $\mathrm{T}$ or enthalpy $\mathrm{h}$ ), turbulent energy kinetics $\mathrm{k}$, turbulent dissipation rate $\varepsilon$ and other variables.

The solving methods of the partial differential equations have been standardized into well accepted methods. These methods are well described by Patankar [5]. A full geometry of the unit process is meshed into a number of two or three dimensional finite cells from low to high mesh resolution. The equations, Eq. 1 are discretised by the finite volume method on each finite cell or other suitable discretisation technique to produce algebraic forms of variable equations. The algebraic forms of variables equation are solved numerically by employing a predictor-corrector solution strategy. The above numerical methods have been used by commercial computational engine software. The famous name for this computational engine is CFD.

One of the key elements in CFD engine is that turbulent flow modeling. The turbulence variables are introduced to follow the law of conservation described by Eq. 1. Many turbulence models have been developed and implemented in CFD engine. Detail about turbulence models development is given by Wilcox [6]. Among the turbulence models, the two variable turbulent model, turbulent kinetic energy $(\mathrm{k})$ and turbulent kinetic energy dissipation rate $(\varepsilon)$, is widely used and mostly satisfies the prediction for engineering problems. This model is well known as k- $\varepsilon$ turbulent model. The transport equations of this turbulent model are stated by Eqs. (2) and (3).

$$
\begin{aligned}
& \frac{\partial}{\partial \mathrm{t}}(\rho \mathrm{k})+\frac{\partial}{\partial \mathrm{x}_{\mathrm{i}}}\left(\rho \mathrm{u}_{\mathrm{i}} \mathrm{k}\right)=\frac{\partial}{\partial \mathrm{x}_{\mathrm{i}}}\left[\left(\mu+\frac{\mu_{\mathrm{t}}}{\sigma_{\mathrm{k}}}\right) \frac{\partial \mathrm{k}}{\partial \mathrm{x}_{\mathrm{i}}}\right]+\mathrm{G}_{\mathrm{k}}+\mathrm{G}_{\mathrm{b}}-\rho \varepsilon-\mathrm{Y}_{\mathrm{M}} \\
& \frac{\partial}{\partial \mathrm{t}}(\rho \varepsilon)+\frac{\partial}{\partial \mathrm{x}_{\mathrm{i}}}\left(\rho \mathrm{u}_{\mathrm{i}} \varepsilon\right)=\frac{\partial}{\partial \mathrm{x}_{\mathrm{i}}}\left[\left(\mu+\frac{\mu_{\mathrm{t}}}{\sigma_{\varepsilon}}\right) \frac{\partial \varepsilon}{\partial \mathrm{x}_{\mathrm{i}}}\right]+\mathrm{C}_{1 \varepsilon} \frac{\varepsilon}{\mathrm{k}}\left(\mathrm{G}_{\mathrm{k}}+\mathrm{C}_{3 \varepsilon} \mathrm{G}_{\mathrm{b}}\right)-\mathrm{C}_{2 \varepsilon} \frac{\varepsilon}{\mathrm{k}} \varepsilon
\end{aligned}
$$


$G_{k}$ : generation of turbulent kinetic energy due to the mean velocity gradients

$G_{b}$ : generation of turbulent kinetic energy due to buoyancy

$Y_{M}$ : contribution of the fluctuating dilatation in compressible turbulence to the overall dissipation rate

The ultimate objective in the unit process is to have good mixing indicated by the uniformity of concentration and temperature. Therefore mass and energy and models must be solved to be coupled with momentum and turbulent solution. For the mass transfer, the species transport equations are then solved simultaneously. The species transport can be with or without chemical reaction.

$$
\mu_{\mathrm{t}}=\mathrm{C}_{\mu} \rho \frac{\mathrm{k}^{2}}{\varepsilon} ; \mathrm{C}_{1 \varepsilon}=1.44 ; \mathrm{C}_{2 \varepsilon}=1.92 ; \sigma_{\mathrm{k}}=1.0 ; \sigma_{\varepsilon}=1.3
$$

For an example, when a conical chamber has to be used as a combustion chamber, such as a secondary reformer in an Ammonia Plant, well mixing, short flame, uniform temperature and velocity of hot gas entering the catalyst bed are key points to achieve an high conversion of methane to reduce the methane concentration leaving the secondary reactor reformer. These process performances links directly to the air burner orientation and the geometry of the combustion chamber geometry.

The meshing process of the geometry of the unit process is based on a numerical grid generation concept [7]. There are many grid generation codes in the market. How complex the design geometry, any grid generator can mesh it. This geometry is meshed in a number of finite cells. The inlet and the outlet faces of the flow are also specified when the meshing process of the geometry is conducted. The meshed cells are transformed to size and coordinates of each cell. The sizes and coordinates of the cells are read by the CFD code. Three dimensional geometry is setup as its size and shape. Every design of the geometry can be easily drawn and meshed into a number of finite three dimensional cells. The CFD code takes all the information about the cell sizes and coordinates.

Once the geometry is designed and meshed, the mesh information is sent to CFD engine. The physical phenomena models are selected in CFD engine whether turbulent flow only, or involving the species mixing with reaction or without reaction and energy transfer. The boundary conditions of the unit process are set up properly in the CFD engine. The right combination of CFD solver parameters are then invoked in order the converged solutions can be obtained. The CFD engine is run for each of designed geometry arrangement. Many commercial CFD engines are available in the market. The detail 
information is given in www.cfd-online.com. For this work, FLUENT CFD software was used as a CFD engine.

\section{$3 \quad$ Methodology}

A unit process performance is indicated by temperature, concentration, velocity levels and distributions and others. A conventional design geometry of a unit process mostly consider the levels of the process variables. Once the level is achieved in the mass and heat balance calculation, the geometry is then designed with very limited understanding and information about the distributions. As a result, the design geometry faces process and operational problems.

The conical chamber has a characteristic to produce a strong recirculation flow. A dominant recirculation flow is sometime not wanted. This is because of large recirculation region with lower value of mass flow rate and dominant channel type of flow at high value of mass flow rate. The presence of the recirculation flow in a chamber is inherently created by the structure of the geometry, the flow inlet arrangement and the flow outlet boundary. Strong recirculation flows can be created inside geometry with cross-section area enlargement which is bounded by a porous media type (like catalyst bed).

To be focused on the exploration of optimization method in design geometry, the size and strength in generated recirculated flows are taken as the response variables. The independent variables are geometry and operating variables. The other response variable that is possible to be considered is the velocity profile to describe the degree of uniformity. The design geometry and operating variables should be arranged or set up to produce symmetrical behavior of the resulted flow pattern.

There are many possible design variables. The possible design variables are air inlet with or without inserted air distributor (air burner), height of air burner from the catalyst bed for secondary reformer with burner, location of air inlet, location of gas inlet, number of gas inlet, number of gas air inlet, catalyst bed diameter, conical angle of the conical chamber, height from the catalyst bed top surface to the mouth of the conical chamber, length of inner transfer line and diameter of inner transfer line. Each design is formed by a set of all possible combination of variables above. The operating variables are then applied to each selected design. The design and the operating variables are optimized using CFD engine. The optimization methodology is described in Figure 2.

The structure of the geometry, Figure 1, is composed by a catalyst bed zone, a conical chamber, a transfer line and a inlet region. The conical chamber has a 
conical angle $\alpha$, the heights to the mouth $\mathrm{h}_{\mathrm{CV}}$, length of transfer line $\mathrm{L}_{\mathrm{TL}}$, and the length of the inlet region $h_{I R}$. The total length of the secondary reformer is denoted by $\mathrm{h}_{\mathrm{TR}}$. The diameter of the catalyst bed $\mathrm{D}_{\mathrm{CB}}$ is $4.05 \mathrm{~m}$. The diameter of the transfer line $\mathrm{D}_{\mathrm{TL}}$ is $0.91 \mathrm{~m}$. These diameters are fixed in this optimization work.

The variables for numerical experiments using CFD engine are the geometry group variables $\Phi_{\mathbf{D G}}$ and the operating group variables. The conical angle belongs to $\Phi_{\mathbf{D G}}$ variables. The angles are $50,60,65,70$ and $74^{\circ}$. In these experiments, the operating variable is air inlet velocity. Only two values of air inlet velocity are employed. These values are $92.95 \mathrm{~m} / \mathrm{s}$ (high) and $17.82 \mathrm{~m} / \mathrm{s}$ (low). The response variables are global flow pattern, velocity profiles and recirculation flow.

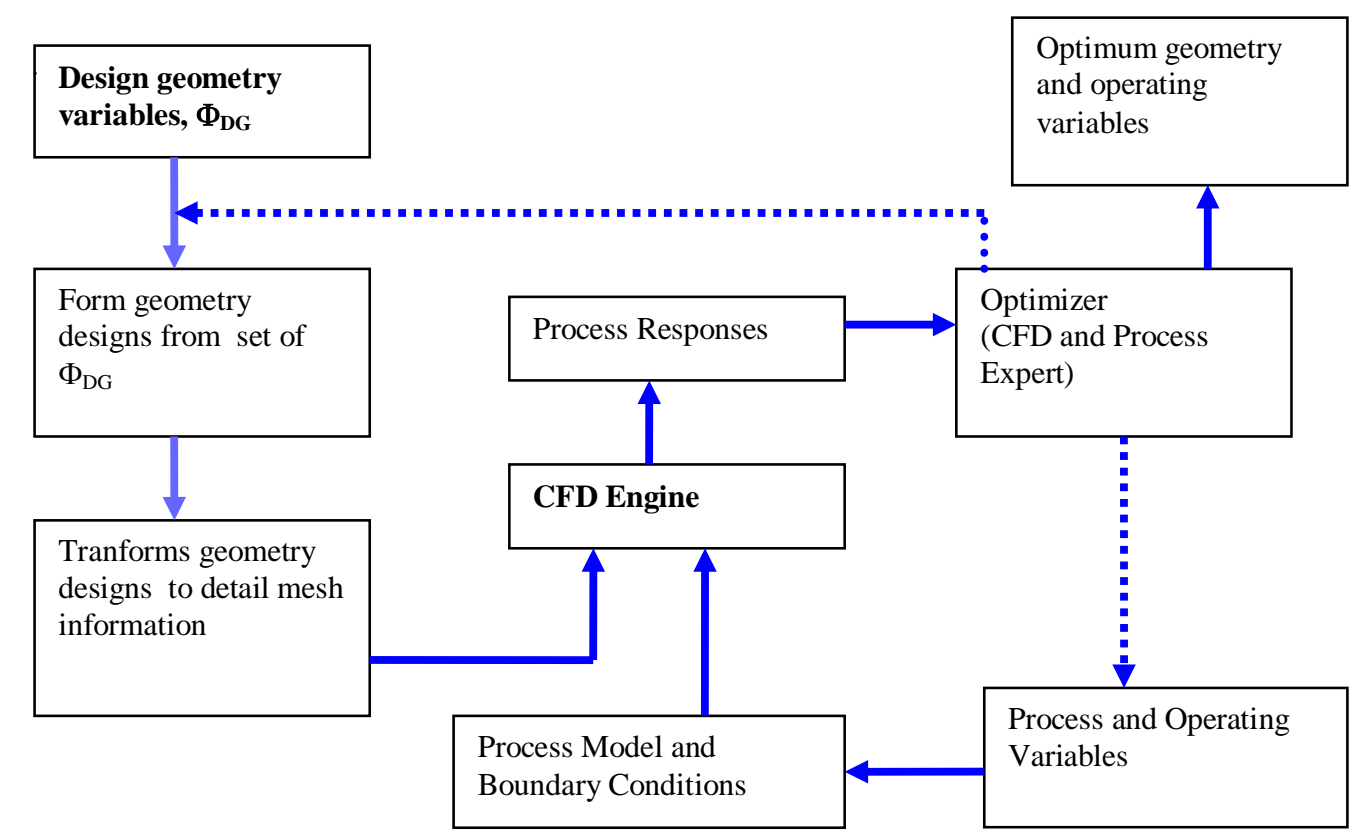

Figure 2 General methodology for geometry and operating variable optimization.

The air inlet exit location from the catalyst bed surface is indicated by $h_{I C}$ in Figure 1. This height was varied. The height of the conical chamber $\mathrm{h}_{\mathrm{CV}}$ and the conical angle $\alpha$ are fixed at the value of $1.87 \mathrm{~m}$ and $50^{\circ}$. As the results, the variation $\mathrm{h}_{\mathrm{IC}}$ can be represented by the variation of $\mathrm{h}_{\mathrm{TL}}$. The values of $\mathrm{h}_{\mathrm{TL}}$ for this specific investigation are $8.808 \mathrm{~m}, 5.818 \mathrm{~m}, 3.322 \mathrm{~m}, 2.170 \mathrm{~m}$ and $0.818 \mathrm{~m}$. The operating variables are selected at high and low velocity inlets. 
At the inlet plane, the $\mathrm{y}$ and $\mathrm{x}$ velocities are fixed to constant values. The turbulent kinetic energy $(\mathrm{k})$ and turbulent dissipation are set to a condition that gives $6 \%$ of turbulent intensity. The values of velocities at the wall are set to zero. Near the wall, the velocity profiles are modeled using a standard near wall velocity function [6].

The porous medium represents the catalyst bed. The fluid momentum and pressure are solved by treating the porous medium as a fluid volume with an additional shear factor [8]. Ergun shear factor model was used in this calculation.

\section{$4 \quad$ Results and Discussion}

\subsection{Flow pattern and profiles}

The focus in this investigation is to characterize the global flow pattern in the conical region. For the purpose of flow pattern and profile presentation, the results for the run at conical angle 50 are taken to describe the global flow pattern. The flow inside the transfer line reaches the fully developed condition before entering the conical chamber. The velocity profiles at the inlet diffuser's entrance are flat. The transfer line function can be stated here as the inlet flow conditioner.

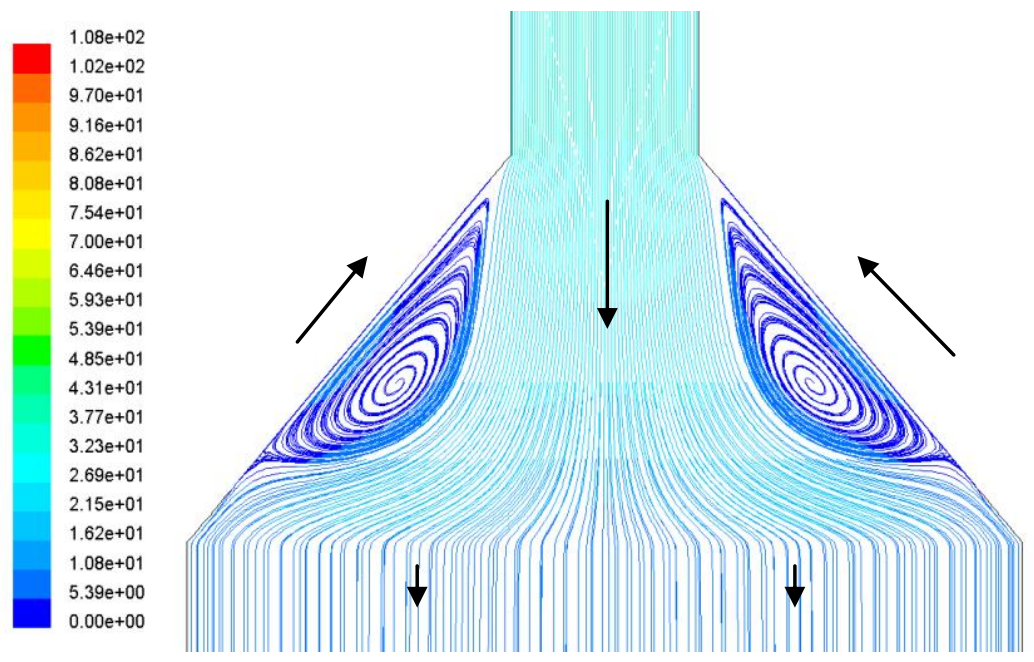

Figure 3 Flow pathline inside a conical chamber at high velocity inlet $\left(\mathrm{V}_{\mathrm{y}}\right.$ inlet $=-92.75 \mathrm{~m} / \mathrm{s}$ ) and conical angle $50^{\circ}$. 

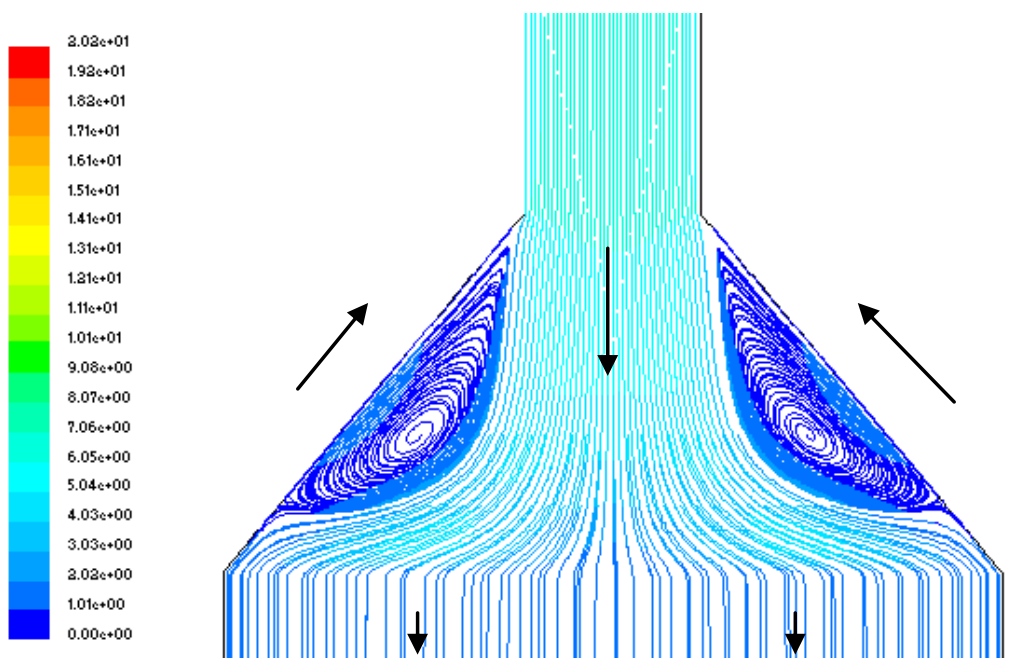

Figure 4 Flow pathline inside a conical chamber at low velocity inlet $\left(\mathrm{V}_{\mathrm{y}}\right.$ inlet $=-17.82 \mathrm{~m} / \mathrm{s}$ ) and conical angle $50^{\circ}$.

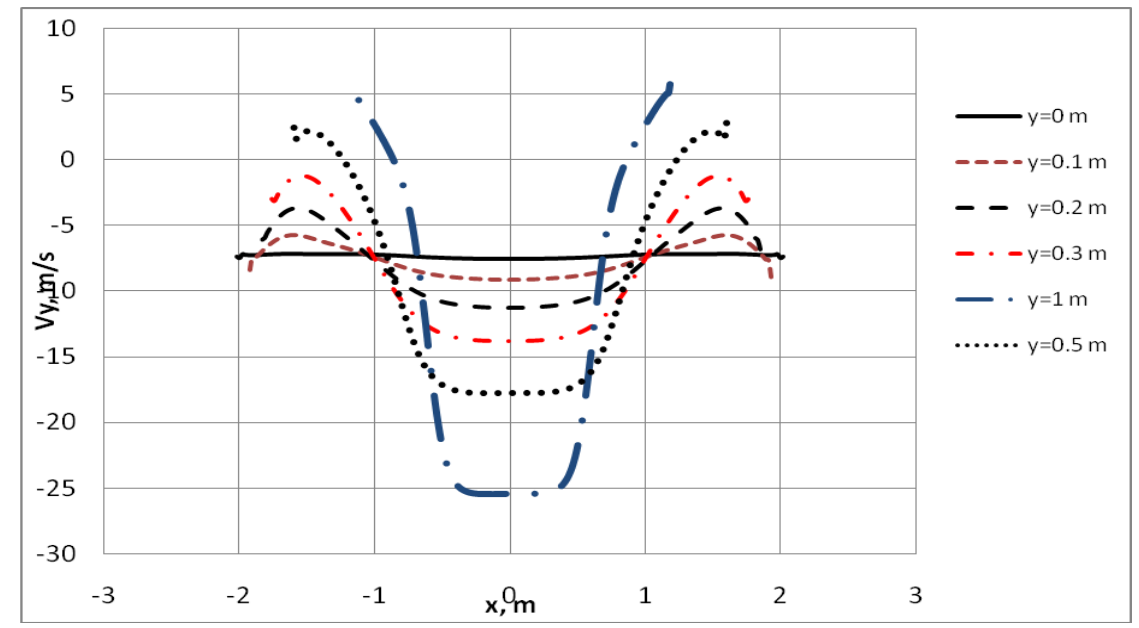

Figure 5 Y-velocity $\left(\mathrm{V}_{\mathrm{y}}\right)$ profiles at various $\mathrm{y}$ - planes $(\mathrm{y}=0 \mathrm{~m}$ at catalyst bed surface) for high velocity $\left(\mathrm{V}_{\mathrm{y}}\right.$ inlet $\left.=-92.75 \mathrm{~m} / \mathrm{s}\right)$ and conical angle $50^{\circ}$. 


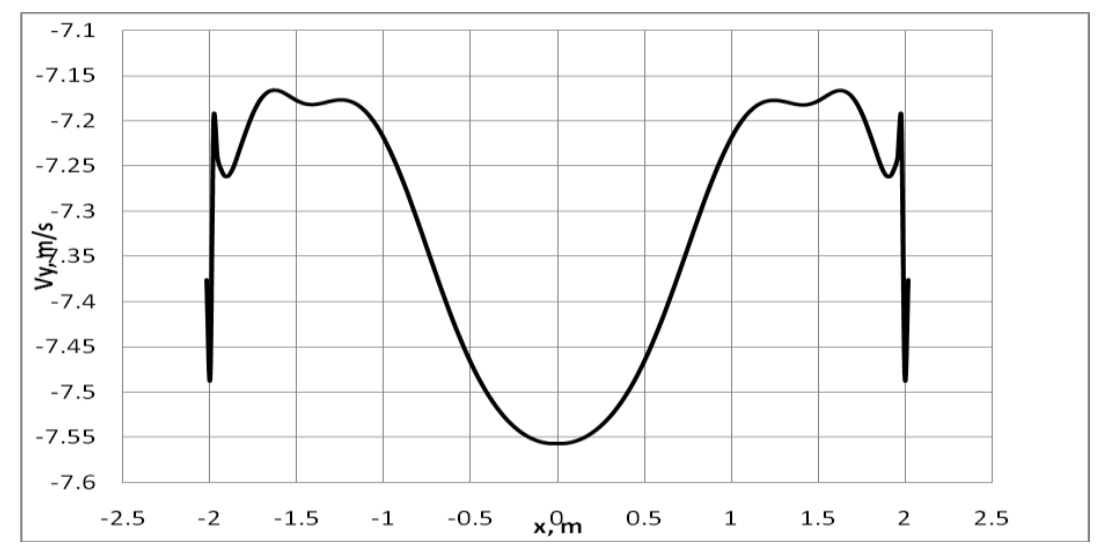

Figure 6 Close look on Y-velocity profile at the catalyst bed surface $(y=0$ $\mathrm{m})$ for high velocity $\left(\mathrm{V}_{\mathrm{y}}\right.$ inlet $\left.=-92.75 \mathrm{~m} / \mathrm{s}\right)$ and conical angle $50^{\circ}$.

The flow pattern inside the conical zone is characterized by the presence of two symmetrical recirculation flow regions near the wall, Figure 3 . The recirculation flow portion is quite significant. However, the primary flow is still dominant. The velocity component profiles are extracted in one dimensional plot. The positive $y$ position is the distance from the surface of catalyst bed $(\mathrm{y}=0 \mathrm{~m})$ toward the upstream of the flow. Zero x coordinate locates at the middle of the diameter. The velocity components that are presented here are velocity components at $\mathrm{y}$-direction and $\mathrm{x}$-direction. The profiles of $\mathrm{y}$-velocity component at various y-planes are shown in Figure 5. These profiles are expected. The velocity distribution at surface of the catalyst bed is more uniform ranging from $-7.16 \mathrm{~m} / \mathrm{s}$ to $-7.56 \mathrm{~m} / \mathrm{s}$, Figure 6 . The uniformity decreases toward the upstream, Figures 3 and 4.

The recirculation regions are indicated by the direction change of the axial velocity $\left(\mathrm{V}_{\mathrm{y}}\right)$ from negative to positive. The positive direction means that the fluid turns its direction backward. This situation is shown by the $\mathrm{V}_{\mathrm{y}}$ profiles, Figure 5, at $\mathrm{y}$-planes at $\mathrm{y}=0.1 \mathrm{~m}$ to $\mathrm{y}=1 \mathrm{~m}$.

The values of inlet velocity do not influence the existence of the recirculation flow in the conical chamber. This is shown by the simulation results at high $\left(\mathrm{V}_{\mathrm{y}}=-92.95 \mathrm{~m} / \mathrm{s}\right)$ and at low $\left(\left(\mathrm{V}_{\mathrm{y}}=-17.82 \mathrm{~m} / \mathrm{s}\right)\right.$ inlet velocities inlet in Figures 3 and 4 .

\subsection{Effect of conical angle}

A conical chamber can act as a flow diffuser. When a porous solid surface is installed as a base of the conical chamber, the flow pattern will be affected by 
the porous solid surface in which the fluid flows through. A basic concept of flow provides an understanding about the recirculation flow. The recirculation flow can occur inside a conical chamber.

A question can be raised here is that do we need the recirculation flow. The answer might be yes or might be not. Another question is about the condition that results no recirculation flow. One of the possible answer is the conical angle. If the conical angle, as defined in Figure 1, the recirculation flow can disappear at large value of the conical angle. Zero conical angle means that the flow area steps up suddenly. For other extreme condition, ninety degree conical angle equals to no change of the flow area or like a straight pipe. The recirculation flow definitely occur at sudden enlargement of the flow area. It will be absent for straight pipe.

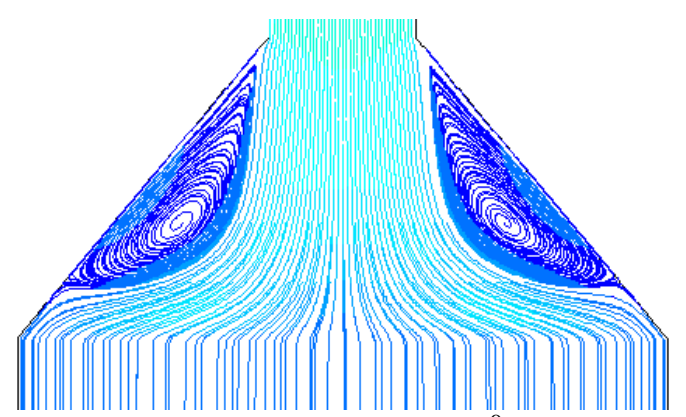

a) conical angle: $50^{\circ}$

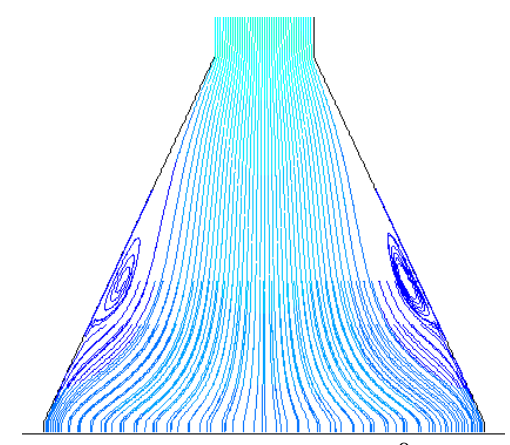

c) conical angle: $65^{\circ}$

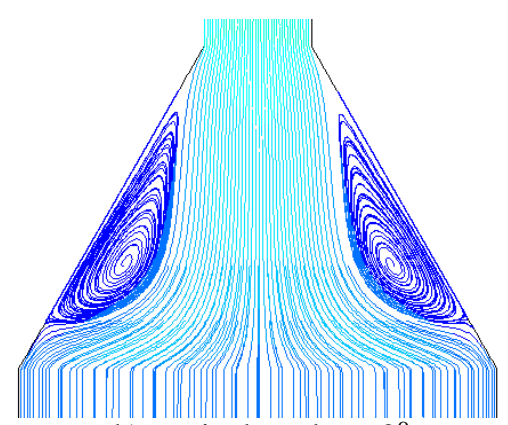

b) conical angle: $60^{\circ}$

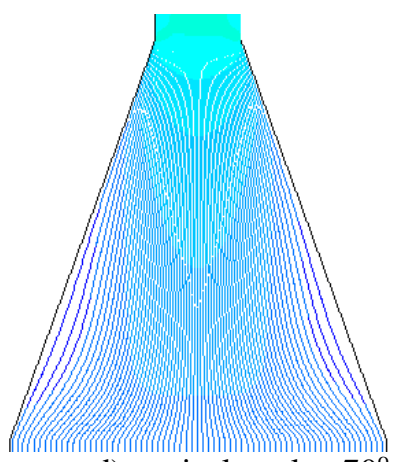

d) conical angle: $70^{\circ}$

Figure 7 Effect of conical angle on flow path characteristics inside the conical chamber at high velocity $\left(\mathrm{V}_{\mathrm{y}}\right.$ inlet $\left.=-92.75 \mathrm{~m} / \mathrm{s}\right)$.

The flow path lines for conical angles of 50, 60, 65, and $70^{\circ}$ are shown in Figure 7. The recirculation flow disappears at conical angle 70. In fact, the size of the recirculation flow reduces when the conical angle is increased. The recirculation size for conical angle $65^{\circ}$ is much smaller than that at conical angle $60^{\circ}$. 
Both high and low inlet velocity values gives similar behavior of the recirculation flow. It can be said that the recirculation flow is very much determined by the geometry rather than the operating variables.

\subsection{Effects of the inlet velocity location}

What are the effects of the length of the transfer line $\left(\mathrm{h}_{\mathrm{TL}}\right)$ to the flow pattern in side the conical room?. To answer this question, $\mathrm{h}_{\mathrm{TL}}$ is varied at values of 8.808 $\mathrm{m}, 5.818 \mathrm{~m}, 3.322 \mathrm{~m}, 2.170 \mathrm{~m}$ and $0.818 \mathrm{~m}$ above the mouth of the conical chamber. Figure 8 shows the flow path lines for the inlet locations at $5.818 \mathrm{~m}$, $3.322 \mathrm{~m}, 2.170 \mathrm{~m}$ and $0.818 \mathrm{~m}$ above the mouth of the conical chamber. The behavior of the recirculation flow changes significantly. At higher distance, the recirculation flow tends to be weak. The strength of the recirculation flow increases when the inlet location becomes shorter. A strong recirculation flow is identified by high internal core velocities or by high curvature that is generated by the internal core and recirculation flow line.

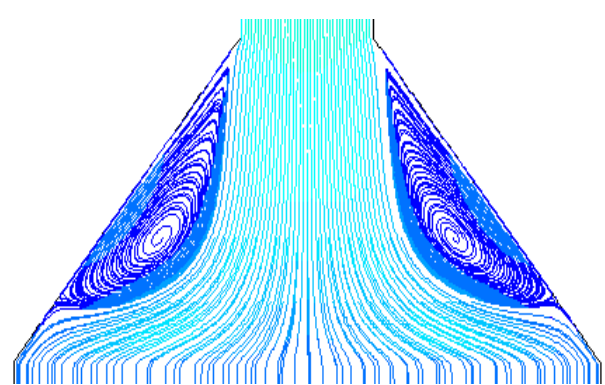

a) length of transfer line $\mathrm{h}_{\mathrm{TL}}=5.818 \mathrm{~m}$

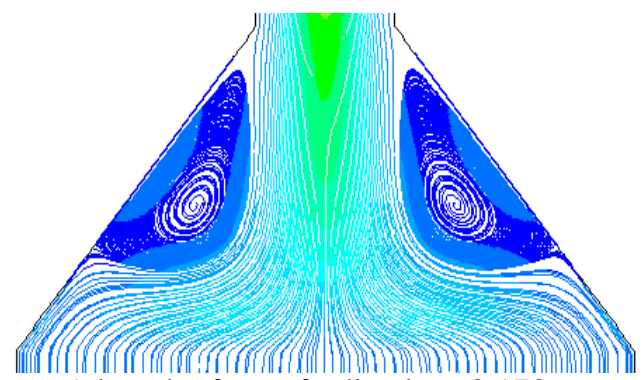

c) length of transfer line $\mathrm{h}_{\mathrm{TL}}=2.170 \mathrm{~m}$

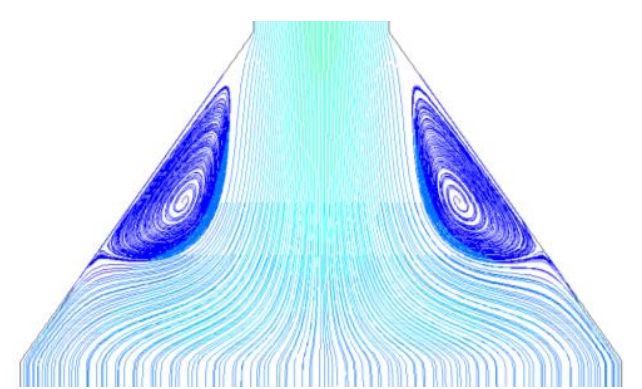

b) length of transfer line $\mathrm{h}_{\mathrm{TL}}=3.322 \mathrm{~m}$

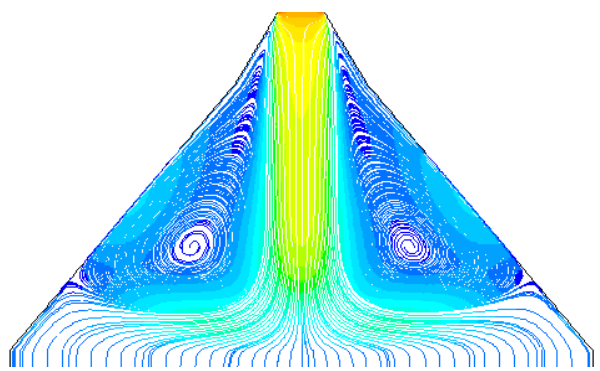

d) transfer line $\mathrm{h}_{\mathrm{TL}}=0.818 \mathrm{~m}$

Figure 8 Effect length of transfer line $\mathrm{h}_{\mathrm{TL}}$ on flow path characteristics inside the conical chamber at high velocity $\left(\mathrm{V}_{\mathrm{y}}\right.$ inlet $\left.=-92.75 \mathrm{~m} / \mathrm{s}\right)$ and conical angle $50^{\circ}$. For flow path $\mathrm{d}$ ), the inlet diffuser was made narrower for more extreme condition.

The extreme condition of the recirculation flow is shown in Figure $8 \mathrm{~d}$. The recirculation flow is very intensive. The central flow is a dominant channeling 
flow. The mass flux concentrates on the central flow. Two flows, recirculation and channeling flows, separate each other. This situation might not be good for the mixing and combustion reaction. The mixing could be poor before entering the bed. The hot spot condition will be severe.

The velocity profiles before entering the bed for different locations of the inlet are compared. The comparisons are shown for y-velocity profiles at surface of the bed $\mathrm{y}=0 \mathrm{~m}$, Figure 9 . The inlet location in these comparisons is stated as the distance $\mathrm{h}$ between the inlet location and the top surface of the catalyst bed. As inlet closer to the bed, the profilitic behavior of the velocity become stronger. The central region on the catalyst surface could be suffered by the impingement effect of a strong jet released from the inlet that is closer to the catalyst bed.

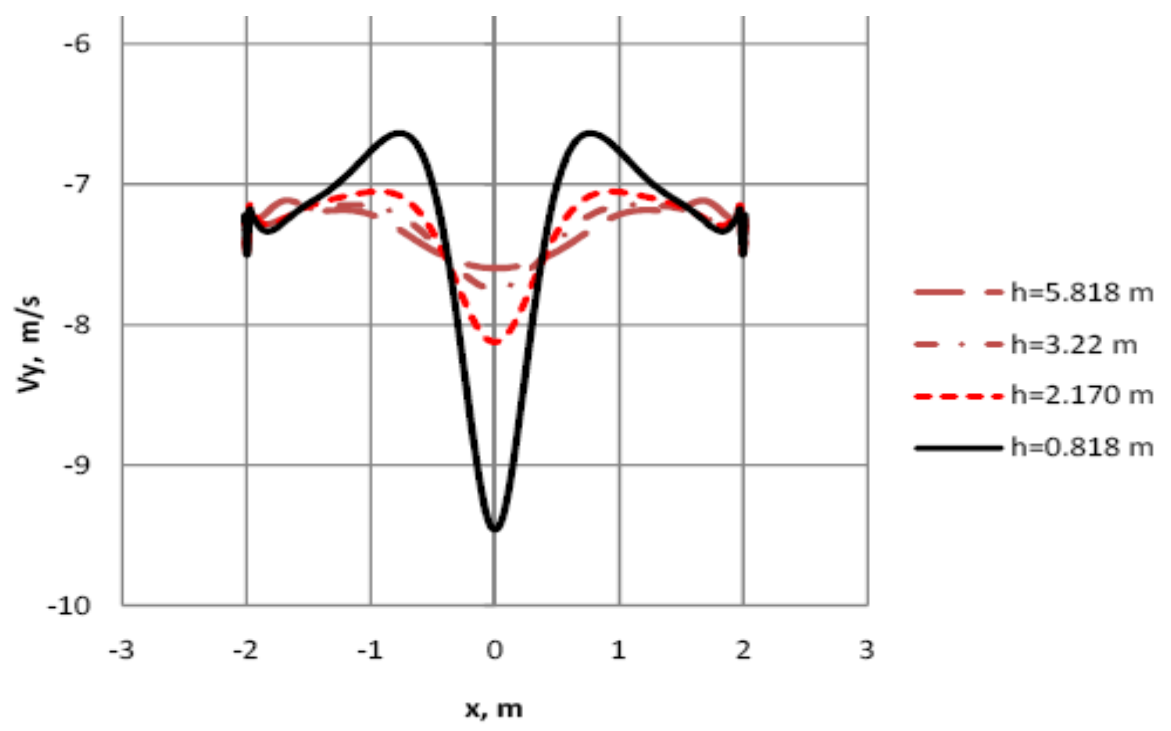

Figure 9 Effect of inlet injection location on $V_{y}$ profile at the catalyst bed surface $(\mathrm{y}=0 \mathrm{~m})$.

\section{$5 \quad$ Conclusions}

A method to optimize the geometry and operating variables using the CFD technique has been presented. The optimization of the geometry of a unit process can be pursued now using the detail process performances based on their distribution spatially and temporally. The superiority of using CFD technique for geometry optimization is due to its comprehensiveness, speed, less cost, flexibility and accuracy. 
The conical angle affects the flow pattern inside the conical chamber having a porous solid surface as a base. A conical angle above $65^{\circ}$ results the disappearing of the recirculation flow. The inlet distance from the porous solid surface also can exhibit different characteristics of recirculation flow. The closer the distance to the porous solid surface, the stronger the recirculation is. The inlet velocity has no significant effect on the presence of the recirculation flow in the conical chamber.

\section{Acknowledgment}

This research was funded by Osaka Gas Foundation.

\section{References}

[1] Reklaitis, G.V., Ravindran, A. \& Ragsdell, K.M., Engineering Optimization: Methods and Applications, John Wiley \& Sons, New York, 1983.

[2] Bird, R.B., Stewart, W.E. \& Lightfoot, E.N., Transport Phenomena, John Wiley \& Son, New York, 1994.

[3] Launder, B.E. \& Spalding, D.B., Lectures in Mathematical Models of Turbulence, Academic Press, London, England, 1972.

[4] Farnell, P.W, Secondary Reforming: Theory and Application, AIChE Symposium, 1993.

[5] Patankar, S.V., Numerical Heat Transfer and Fluid Flow, Hemisphere Publishing Corp, 1980.

[6] Wilcox, D.C., Turbulence Modeling for CFD, DCW Industries, Inc., La Canada, California, 2002.

[7] Thompson, J.F., Warsi, Z.U. \& Mastin, C.W., Numerical Grid Generation: Foundations and Applications, Nort-Holland, Amsterdam, 1985.

[8] Bindar, Y., Makertihartha, IGBN, Supardan, M.D. \& Buchari, L., Utilizing Shear Factor Model and Adding Viscosity Term in Improving a Two-Dimensional Model of Fluid Flow in Non Uniform Porous Media, ITB J. Eng. Sci., 39(2), 2007. 